\title{
The Changeover: The Stepchildren's Socio-cultural Adaptability Skills Towards their Stepparents
}

\author{
Monaliza P. Cayatoc MAg RGC, Marc Angelo C. Igna, Bianca Pauline B. Colle, Charlene Chloe \\ I. Dolom, Deheimer L. Edra, Angelica Marie G. Samonte
}

\begin{abstract}
Background: What was once a contented and faithful family is presently missing a piece in their household. After the parents' decision to separate, their biological parents eventually married someone else after a respite. Having their stepparents by their sides, the stepchildren felt uneasy while adapting to a different environment. Purpose: This research aims to discover and understand the lived experiences of stepchildren as they undergo the process of adaptation with their stepparents. Method: This qualitative research which utilized phenomenology, pertains to our central question: "What are the socio-cultural adaptability skills that stepchildren have undergone as they are prompted to be with their stepparents?" A twenty-five semi-structured interview guide questions were also used to gather and analyze data. Inductive approach was followed in the theme development. Findings: The study has uncovered four stages on the process of adapting of the stepchildren to their stepparents namely; Knowing Stage, Struggling Stage, Understanding Stage, and Adapting Stage. Conclusion: The stepchildren's socio-cultural adaptability skills towards their stepparents underwent many struggles that greatly affected the stepchildren's development as an individual. The stepchildren struggle to adjust and adapt to their stepparents through the introduction, hesitance, exclusivity, non-conformity, unconsciousness, initiative, cultural commonality, acceptance, cultural diversity, and openness. Recommendation: This research suggests that their biological parent must gradually introduce the stepparents to their stepchildren. Giving their stepchildren time to adjust allows more space for acceptance on the part of the stepchildren.
\end{abstract}

Index Terms- Adaptability Skills, Stepchildren, Stepparents, Socio-cultural, Step Family.

\section{INTRODUCTION}

In the 21 st century, the word family has embodied different categories which are nuclear, extended, childless, single parent, and reconstituted family. Defined, it is a group of people that tend to the needs of each other. This social unit provides love, company, support, and framework that are essential for its members.

Commonly, families are composed of a parent and child. Both significantly influence each social, emotional, and cultural manner. It is amplified or weakened by multiple

Monaliza P. Cayatoc MAG RGC $_{1,2,3}$, Marc Angelo C Igna, $1,2,3$ Bianca Pauline B. Colle, 1,2,3, Charlene Chloe I. Dolom, ,2,3, Deheimer L. Edra $_{, 1,2,3}$,Angelica Marie G. Samonte, $, 1,2,3$

1. Philippine School Doha, Doha, Qatar

2. Research Development Accreditation and Publication Office, PSD, Doha, Qatar

3. Research Capstone Project, PSD, Doha, Qatar factors such as time and mutuality. Reconstituted family as the subject being in focus is also known as a blended family or stepfamily. The prefix "step" came from the Latin word step, which refers to an orphan and denotes a connection made from the remarriage of a widowed parent, resulting in a stepparent-child relationship. Lack of significant time and familiarity is the distinguishing characteristic of this dynamic. There are implicated stages to adjustment of stepchildren, namely knowing, struggling, understanding, and adapting stage. These are guidelines to specify a period wherein a skill materializes. By supplementing inadequate time and understanding elements, the children can exercise adaptability, reaching a point of satisfactory assimilation.

It is possible to take some time to get adjusted to the new situation as the biological parent introduces the step-parent to the child. There are times that the stepchild rebels. Based on Kelly's blog Nobody Asked Me: Thoughts of a Stepchild (n.d), A blended family is only successful if all members have grown to treat each other lovingly and respectfully. Even though knowing the step-parent is somehow difficult for a child to comprehend, the stepchild has a right to know the new person that is entering his or her life. Having a new parent can be hard to get accustomed to. Possibly, the child will wonder about rules and whether he or she needs to listen to his or her step-parent.

Another adult who is looking out for a child is the step-parent, so it is best to give the step-parent the same level of respect the child gives his or her parents, coaches, or teachers at school (Sherman, 2016). It may be hard to accept, but given that the step-parent is trying to connect with his or her stepchild, it may help to let the stepchild adjust over time. From the perspective of Grace (2017), the ideal situation is when the children in stepfamilies are encouraged to express their feelings. Then, parents and step-parents, as a result, do everything they could to help the kids feel good about their family situation.

A study conducted by Mboniswa (2018) explored the experiences of growing up as a stepchild for young adults. Nevertheless, this research study focuses on the socio-cultural adaptability skills of the stepchildren with their foreign step-parents. Most articles focus on the view of step-parents; hence, conducting this study can contribute to the knowledge of future researchers. Being able to understand the experiences and struggles of a stepchild deeply will widen the awareness of people who are not familiar with the situation.

As stated in the American Psychological Association (APA, 2013), step-parent should not establish a connection with their stepchildren rigorously but create a relationship in a 
friendly way. The couple may also agree to give the discipline and control of the children until the step-parent and the child develops a solid bond. He or she can monitor the child's behavior and doings as they gradually take on more parenting responsibilities.

Not all kids are open to their parents; thus, parents have to be the ones to initiate the conversation and bond with their kids. Children usually hesitate during the first phase; they do not engage with their step-parents until their step-parents initiate talking to them. Creating a bond is a way of resolving and lessening problems. It can also be a contributor to the child's social skills and widen knowledge about cultural practices.

\section{METHODS}

\section{Research Design}

This study's design is qualitative and phenomenological in nature. Qualitative research is one of the social science researches that gather and deal with non-numerical data, and it seeks to interpret explanation from these data that help us understand social life. (Crossman, 2019). Phenomenology is a type of approach to qualitative research that deals with the commonality of a lived experience within a particular class. The fundamental goal of this approach is to arrive at a description of the nature of the particular phenomenon (Creswell, 2013). The study addresses the different perspectives and insights of the respondents that are used to formulate a new meaning that can be used to describe a particular group and nature of the particular phenomenon related to the research.

\section{Research Locus and Sample}

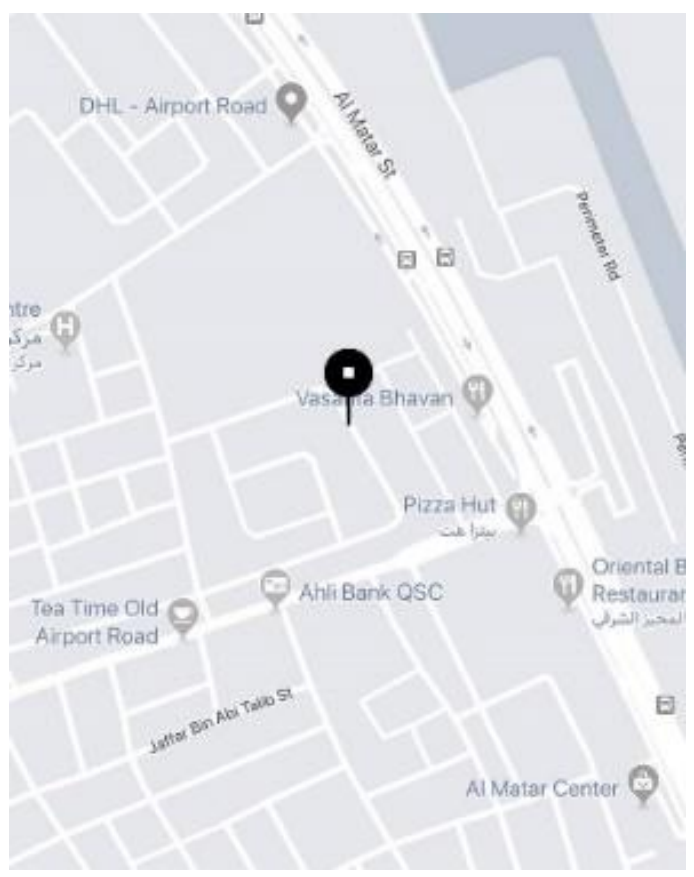

Figure 1: Philippine School Doha

The research was conducted in Philippine School Doha (PSD) - one of the most exceptional Filipino schools in the Middle East. Philippine School Doha is an educational institution that provides outstanding faculty members that accompany and assist numerous students in their different studies. The learning institution also provides exemplary facilities that enable students to immerse and engage in their different academic studies. The school was selected by the researchers considering the numerous opportunities that could contribute to the authenticity and credibility of the study.

The selected participants of the research are the ones who have step parents with different cultures. Specifically, these teenagers are the students of the senior high school department of the Philippine School Doha. The selection of the five participants was made through a qualitative simple purposive sampling strategy. This strategy is used when the participants have the specific criteria of being chosen by the researchers. The participants of the study were chosen, considering that the students are part of the senior high school department, the students have step-parents who have different nationalities, the students have step parents of different cultures.

\section{Data Collection and Ethical Consideration}

A semi-structured interview is used by the researchers in order to acquire the necessary data. A semi-structured interview is a meeting in which the interviewer does not strictly follow a formalized list of questions. They will ask more open-ended questions, allowing for a discussion with the interviewee rather than a straightforward question and answer format (Doyle, 2018).

Different instruments, such as the robotfoto and the twenty-five semi-structured interview guide, were used to support the data that were obtained. The robotfoto refers to the personal data sheets of the research respondents, which include their vital personal and professional information (De Guzman \& Tan, 2007). It is composed of their name, grade level, ages, civil status of the parents, and the nationality of the parents.

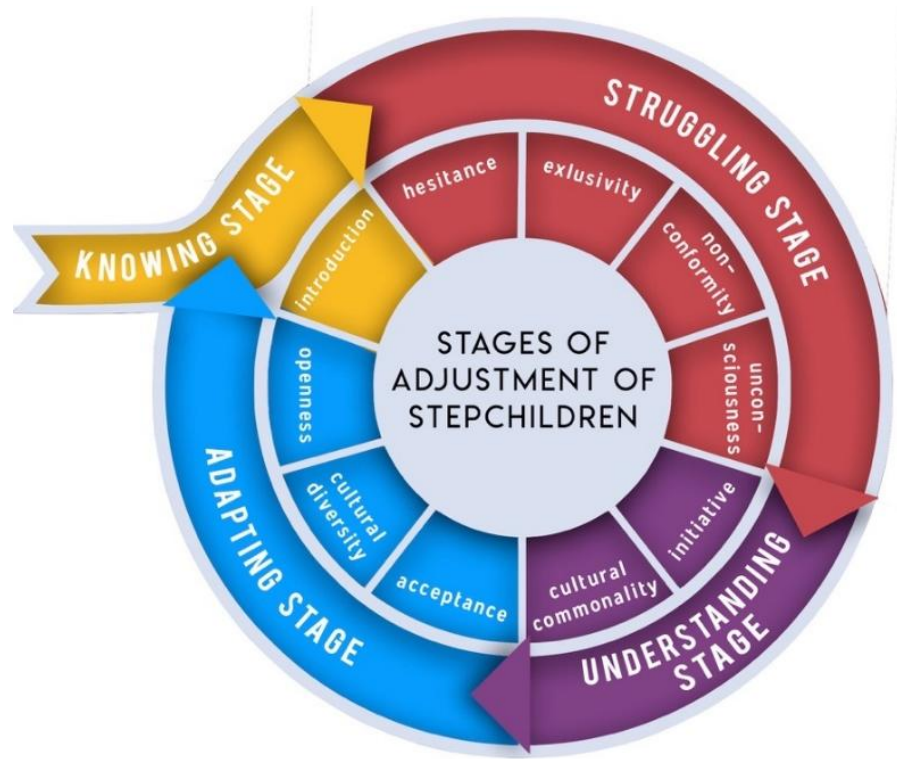

Figure 2. Adaptability Skills of Stepchildren

The researchers used recording equipment together with the twenty-five semi-structured interview to accompany the researcher and the data that were collected and transcribed verbatim in order to maintain the integrity of the semi-structured interviews. Beforehand, the participants were 
given a written consent letter to ensure that they are willing to do the interview in their preferred date and time.

\section{Data Analysis}

The researchers have used the inductive approach in theme development (Braun \& Clarke, 2006) to capture and analyze the collected data in the study: (1) evaluating and reviewing the transcribed data to attain the respondent's insights; (2) verifying small units which is called meaning units; (3) reforming meaning unites from respondent's point of view to the naïve understanding of the researchers; (4) organizing the formulated meanings by arranging the data into groups, clusters, and themes through the use of dendogram; (5) create a simulacrum to present the theme visually; (6) developing themes must go through triangulation and member checking procedures to assure credibility and legitimacy.

\section{FINDINGS}

When two people enter the matrimonial state, they start a family and hope to be with each other's side forever. However, sometimes, problems happen that are too much to handle even if they have children. They realize that separation is the best solution to their situation. Sometimes when that happens, the mother or father then marries someone else; thus, the creation of a new family. Cools (2018) mentioned that it is a big adjustment. For some families, creating a stepfamily is the best thing that could happen. For others, it never occurs, and the family breaks down.

The simulacrum pertains to the different aspects of adjustment done by the children towards their stepparents, specifically their stepfather. There are four themes extracted from the research - knowing stage, struggling stage, understanding stage, and adapting stage, respectively. In the first stage, children firstly introduce to their stepparents and with the cultures, they have in common such as beliefs and practices. After some time, the children and the stepparent would go to the second stage, discover and experience cultural differences. They experience struggles and endeavors in the problems they encounter in building and stabilizing their relationship. Over time, children acquaint with their cultural commonality. Understanding the situation and the challenges that come with it leads to the last stage of the cycle -- adapting stage. In this situation, the children apply the ideas they discovered and learned throughout the experiences they had between their stepparents. After experiencing every aspect,

this is the fragment where all of the ideas and concept s would reside in children's minds. It would help to form the values the child will carry throughout his or her life.

Figure 5 shows the simulacrum is a circle and has arrows that represent the continuous flow of the adjustment of the child. The child does not learn different aspects of the culture right away. Once the child learns an aspect, they would eventually encounter new portions of the culture going through the whole flow again since cultures are broad and diverse.

\section{KNOWING STAGE}

Filipinos are known to be joyful and approachable, especially when it comes to meeting new people. Although it might be challenging to cope with these situations, Filipinos still can surpass these circumstances. There are many stages that one has to overcome to fully accept and understand these kinds of situations. During the Knowing Stage, this is the period where the biological parent unveils the step-parent to their children. With respective step-parent and child become aware of their fundamental nature throughout this stage, this can affect the overall relationship dynamics. There are various ways to introduce the step-parent to their stepchildren.

\section{"My mom first introduced him to me as her friend and slowly as her boyfriend, and then he became my dad." (Participant No. 5)}

The step-parent must introduce themselves gradually to avoid shocking the children because of the change situation dealing with all of his or her life to prevent any misunderstandings. Although some are introduced gradually, some people are directly introduced to their step-parent.

"It just happened. My mom introduced me to my
step-parent." (Participant No. 3)
"When I arrived here in Qatar three years ago.
(Participant No. 4)
"My mom brought me to Manila to introduce him
as her boyfriend." (Participant No. 5)
"I was introduced to my step-parent by my mom,
telling me that she has a boyfriend. Then I realized
that I got introduced to him when they were already
together." (Participant No. 3)

On the one hand, some people may prefer to introduce themselves straightforwardly because he/she knows how their children react on some circumstances while on the other hand, certain people were not able to experience being introduced to their step-parents.

\begin{abstract}
"My mom's and my stepdad's house are just near each other. I have known him as an uncle, and he was the one who drives us to wherever we have to go. I thought they were just friends. Little did I know they were already in a relationship." (Participant No.2)
\end{abstract}

\begin{abstract}
"When I got back here, he was introduced to me as my uncle. At first, he was introduced as just an uncle, but afterward, I was suddenly told that they were already getting married. So I didn't really have a choice. "(Participant No. 2)
\end{abstract}

Even though it is hard to grasp the idea of having a new parent, every child has a right to know who is coming into their lives. With all the given responses, it is evident that step-parents are introduced in the most appropriate way that the biological parents can give because they are the ones who know their children more than anyone. Whether the introduction was directly or gradually, it is the manner of dealing that will matter the most. However, there can be misunderstandings that will come along the way, and the 
knowing stage will proceed to the struggling stage subsequently.

\section{STRUGGLING STAGE}

As the children start to discover and learn more about their step-parents, they start to face difficulties with regards to their relationship with their step-parents. The children's everyday experience as a family changed when their step-parents arrived. One of the difficulties children experience towards their step-parents is hesitance. Accordingly, children are hesitant in terms of opening up to their step-parents for that their step-parents might have different perspectives on the situation or opinion that the child has mentioned. Some examples of this would be being judged or being scolded by their step-parent. Alternatively, in some cases, the step-parent will not care about their stepchildren opening up to them.

"No, because we are not close. Due to his strictness, I'm afraid to share something because. might judge or get mad at me." P4

"No, because I feel like even if I share it with him, he would not understand my problem." P4

"Yes, because he is not that open. Every time I would open up to him, he would say "ah okay," and then he would ask me what I want to eat." P2

Although it is common to struggle in terms of adjusting to a new situation, it does not apply to all children or step-parent as we have different perspectives in dealing with different situations.

\section{"No, because he believes that I should be firm on my beliefs and he respects that." P2 \\ "My step-parent does not encourage me to believe his own cultural beliefs, although he likes to share his culture when we chat, and he does not force his culture upon me." P3}

When it comes to sharing their beliefs, step-parents do not encourage their stepchildren but rather let them choose their own. It is exclusive in a way that both parties are minding their businesses without forcing his/her own beliefs.

\section{"Not really, because sometimes he would attend Catholic mass with us, and we would go to their temple. He does not force us to his beliefs. " Pl \\ "No, because he believes that I should be firm on my beliefs, and he respects that." P2}

Since both sides have shared their own culture and beliefs, the children will know their cultural differences, which prompts it to the next sub-theme, which is the cultural differences.

In terms of cultural differences, some step-parents do not encourage or force their stepchildren to follow their cultural beliefs. As stated from the responses of the participants, their step-parents either respected their cultural differences or shared their own cultural beliefs.

On the first hand, both parties had to adjust to their family. On the other hand, the child did not need to accustom themselves since their step-parent had already adjusted for them.
"No, because my father adjusts for us." PI Nevertheless, there are times when even though the child is not yet used to having a step-parent, they accept it regardless for the sake of their biological parent's happiness.

\begin{abstract}
"When I was stubborn and rebellious, my mom was the one who talks to me every time I tell her that I do not like having a step-dad. However, now that I see that my mom is happy, I did not pursue telling her about not liking my step-dad." P2
\end{abstract}

From the responses of the participants, children do experience struggles when it comes to adjusting to a new step-parent, such as hesitating to open up to their step-parents or accepting the fact that they already have a step-parent.

Nevertheless, in some cases, the children will not experience any struggles or adjustments since their step-parents adjusted for them. Having cultural differences can be difficult, but it will be not if they deal and approach it correctly.

Having a step-parent, it does not always mean that one will have a smooth ride along the journey of adjusting to a new life. It comes with some problems and miscommunications, and with that, some step-parents are not conscious enough to either know or deal with these problems.

\section{"He usually responds to the problem of having a family meeting." P3 \\ "He would always talk to me about it, but sometimes if the problem is too big, we tell my mom, and we would talk about it as a family." P5}

From the responses of the participants, their step-parents choose to discuss it as a family. It shows that the step-parents want to deal with the problem in the most mature way that is possible. Subsequently, stepchildren have adapted in all aspects towards their step-parents, and because of this, they will be able to the next stage, which is the Understanding Stage.

\section{UNDERSTANDING STAGE}

As the child goes through the struggles of having a stepparent, he or she begins to acknowledge that he or she will be living with the stepparent for long, and it is better to accept the situation and the stepparent. It would be difficult at first, yet the child will slowly learn to accept the stepparent and understand the situation.

"When I was stubborn and rebellious, my mom was
the one who talks to me every time I tell her that I
don't like having a step-dad. However, now that I
see that my mom is happy, I did not pursue telling
her about not liking my step-dad." P2

With this response, we could see that the respondent did not accept the stepparent at first, yet he or she learned to accept and understand the stepparent because he or she sees that his or her biological parent is happy with the stepparent. 
"It is a blessing to me that my mother and I would talk about my struggles and feelings, often especially the times when I need to vent because I was confused with what was happening." P5

Sometimes, the child needs someone, like a mother, to help him or her throughout the adjustment stage. At a young age, the child could be confused with adjusting to a stepparent, so it is nice to have someone to guide him or her properly.

Furthermore, as the child accomplishes to accept the stepparent and be more open, he or she starts to initiate interactions and conversations with the stepparent comfortably.

\section{"Yes, especially now that I am a teenager, I need to open up to him more. Sometimes we sit together in the living room and talk about random stuff, such as things about the school, life in general, and even about my love life." P5}

We observe that as the child grows with the stepparent, he or she becomes more open and starts to share parts of their life with the stepparent for them to know each other more.

\section{"I take the initiative to start a conversation sometimes when I need something, or I want to ask something. " $P 3$}

In other instances, the child is not open with the stepparent, which may be caused by the insufficient quality time spent together by the child and the stepparent, but not too close that the child does not talk to the stepparent.

As the child understands the stepparent, he or she initiates to adapt or to understand the culture brought by the stepparent. They begin to share the different cultures and traditions they have, start to find their cultural commonality, and start to apply them in their family life and identity.

"I have conformed to my step parent's culture, but I am not sure how. I naturally adjusted to his culture." P3

We can see in P3's response that the stepchildren naturally adjusted with the stepparent's culture through the time that they have been together.

\footnotetext{
"Yes, we do not like to waste food. We think about the people who cannot eat as much as we can, so we learned to be considerate. I believe it is a good practice, especially for me and for my step sister." P5
}

We can also observe in this response that the stepchildren learned the culture and values brought by their stepparent, and they recognize it as a good practice.

The stepchild starts to consider the stepparent as part of the family and applies the culture. The child can now proceed to the last stage of adjusting of stepchildren to stepparents, which is the acceptance stage.

\section{ADAPTING STAGE}

Children who are grieving the loss of a deceased parent or the separation or divorce of their biological parents may need time to heal before they can fully accept their step-parent. They affirmed:

"We get uncomfortable if we do not talk to each other even if we are together, and we got over it because we lived together for a long time, and we got used to it." PI

"I learned to accept the change that happened in my life. I was blessed to have another person in my life who loves me, so I was okay with it, and I easily coped with the change." P5

"I got over the feeling uncomfortable around my step-parent by getting used to the new situations." P5

Though having different cultures and religions, this did not become a hindrance in building a relationship with their step-parent because they have also conformed to their step-parent's rules which has been evident in their respondents:

"I have never felt uncomfortable with my step parent's culture since I have stayed in Qatar for a long time to experience similar cultures to his culture." P3

"I adjusted in terms of clothing since Muslims do not wear revealing clothes, and I should come home at a certain curfew they give me, but it was fine." P2

"I apply a little bit of both, but I practice my culture more because the customs and traditions we have in the household, such as the events or holidays we celebrate are from the Philippine culture." P5

Over time, they can develop a deeper, more meaningful relationship with each other, which does not necessarily have to resemble the one they have shared with their biological parents. They expressed:

"I do share my problems with my step-parent, and when we do, it's usually a man-to-man talk." P3 "Yes, because I am open to my parents with what is happening in my life. I share everything, and that is why it was not a struggle for me to share my problems with them." P5

"We would often talk, be open with each other, emotionally and physically, as much as possible." P5

Building a relationship with a step-parent is different from building other new relationships. Michaels (2006) revealed that healthy stepfamilies were successful due to behaviors of acceptance, flexibility, respect, patience, communication, and having a sense of humor. It is hard to be open to someone you have just met because a step-parent can sometimes feel like a stranger who suddenly slides into your life. Everyone experiences a different situation; that is why there may be no easy answers to accepting a step-parent. 


\section{DISCUSSION}

Step-family, unlike the common misconception, is not a new occurrence. About 1300 new step-families are forming each day as dictated by the US Bureau of Census (2009). There are multiple reasons for its formation. Remarriage rates for divorced persons are consistently higher than rates of remarriage for widowed persons (Frenier, 1980). As separation and divorce became prominent, more step-families resurfaced. Such allows an opportunity to remarry for the sake of creating a substitute parental figure necessary for the children left behind.

There are complications step-families usually face among are their parenting techniques, comparison to biological family, age gap with children, cultural dynamics, and a time frame wherein it is expected to the members to feel fit into each other. Mills D (1984) suggested that the time required for the child to fully adjust equally to the age of their transition to becoming a step-family. They are learning to deal with the cultural differences between supports the child to acknowledge where he or she identifies with. Thus, it establishes the flexibility between biological and stepparent nature towards an agreement.

Underdetermined stages come aspects which the children experience throughout the whole process of adjusting to their stepparents, considering the cultural and social divergence linking further to how openness, cultural diversity, unconsciousness, acceptance, nonconformity, hesitance, initiative, and exclusivity with accompanying demonstration affect the success of the confirmation into a stepparent-child relationship.

\section{KNOWING STAGE}

Parents and stepparents must take charge of introducing the children. Children who see parents happy in a second marriage will be more receptive to stepsiblings (Valerie, 1999). The biological parent is usually the one who introduces the stepparent to the child.

For most parents, introducing a new partner into their children's lives is an incredibly important decision. In our experience, contrary to the way these things are often portrayed, lone parents are not always hopping in and out of relationships, they think rigorously before jumping on something new, and their foremost concern is how it is going to affect their children (O'Kelly, 2005). Lone parents face difficulty in entering new relationships, possibly due to their past relationship experiences and assumption of the need to scrutinize its consequences.

Stepparents may likely adhere to establishing a deeper relationship with their co-parent compared to building rapport with their stepchild. Sheppard, Garcia, and Sear (2014) said introducing a stepparent into the household may lead to drift away from the biological parent in existing children since they will be diverting some resources from parenting effort into the mating effort and their relationship with the new partner.
When first introduced to the children, "Stepparents often feel a lot like a kid waiting to be picked for the kickball team," McBride said. "They try way too hard. Kids can smell that a mile away." A biological parent should make expectations clear about how children are to treat the stepparent without trying to force a loving relationship. (Olson, 2002). The biological parent shall be the medium between two parties that are getting to know each other yet as they are familiar with the characteristic that may merge both sides. It is their responsibility to settle into an agreement about the role and limitations obligated to the stepparent in respect to the child, vice versa.

\section{STRUGGLING STAGE}

Although there is a possibility of creating a tense relationship between the residential and nonresidential households after a divorce, things may become even more challenging after the addition of a stepparent to the residential family (Coleman, Fine, Ganong, Downs, \&Pauk, 2001). Hetherington and Clingempeel (1992) and Walker and Messinger (1979) found uncertainty in stepfamilies over what the child and stepparent should feel and expect from each other. The uncertainty in expectations for disciplinary, open, and affectionate, communicative behaviors from a stepparent can lead to conflict between family members (Sroufe\&Fleeson, 1988). While conflict itself may not be problematic for family adjustment, the inability to address and overcome it may be. Further, as a family struggles to resolve their conflicts that arise from discrepant expectancies, members may also negatively contribute to the overall functioning of the family (Sroufe\&Fleeson, 1988).

Communicating and negotiating boundaries can be a challenge to family members who have experienced a divorce and remarriage. In particular, stepchildren and their nonresidential parent's family must manage potential changes and challenges to their communication and relationship as the stepchild transitions into stepfamily life (DiVerniero, 2010). Avoiding conversations may be predictive of difficulties in solving relational problems - poor communication quality is related to problems between stepparents and stepchildren (Gosselin \& David, 2007). Furthermore, there is an avoidance of some topics because they look as destructive relational forces, and topic avoidance serves a relationship maintenance function (Baxter and Wilmot, 1985). Two of the reasons why people avoid specific topics are for self-protection and relationship protection (Guerrero and Afifi, 1995a, 1995b). As Baxter and Wilmot (1985) and Afifi and Burgoon (1998) asserted, topic avoidance serves as relationship maintenance to steer clear of potential problems within the family.

Despite cultural differences, the stepparent respected their differences and did not force their own cultures to their stepchildren - allowing them to continue to believe in their own cultures. Authoritative parenting consists of strictness, along with warmth and nurturing for the child. In contrast, authoritarian consists of strictness along with a cold approach. Authoritarian stepparenting tends to increase the amount of avoidance, whereas more non-restrictiveness and authoritativeness decreased it. Authoritativeness and authoritarianism were more strongly correlated than 
non-restrictiveness with participants' avoidance. (Golish, 2003) The relationship between parenting styles and adolescent adjustment in stepfamilies suggests the dangers of too much control without support, or too little control, and the benefits of support and warmth. Similar to the parenting literature in general, an Authoritative style seems most conducive to adolescent adjustment (Crosbie-Burnett and Giles-Sims, 1994). Hetherington and Clingempeel (1992) discovered that an Authoritative parenting style for mothers and stepfathers was associated with the best outcomes for early adolescents. Concerning stepparenting styles specifically, the sparse research suggests a positive relationship between adolescent adjustment and either an Authoritative style or absence of direct involvement in the control dimension (Crosbie-Burnett and Giles-Sims, 1994).

Not surprisingly, stepchildren do not like to be disciplined by stepparents (Claxton-Oldfield, Garber, \&Gillcrist, 2006). They prefer open and flexible communication with stepparents (Baxter et al., 2004; Henry \& Lovelace, 1995), and talk more with stepparents who use authoritative and permissive styles of stepparenting than with authoritarian stepparents (Golish, 2003). Many of the stepchildren, particularly the adolescents, did not accept them as parental figures and were negative, even hostile, toward their stepparents (Hetherington \&Clingempeel, 1992). Stepchildren often act against stepparents who are perceived to be overbearing in their parenting roles (Golish, 2003). Golish (2003) further mentioned that stepparents commonly receive more negative feedback from their stepchildren in disciplinary exchanges as they do not impose the same authority as a biological parent.

\section{UNDERSTANDING STAGE}

Step-children will have to adapt to the culture brought by their step-parent. Berry identified two dimensions underlying cultural adjustment processes (Wilchek-Aviad\&Timsit, 2018); (a) cultural maintenance, which refers to the degree which people appreciate and desire to preserve their identity and (b) cultural customs, and contact participation, which refers to the degree to which people appreciate and desire to maintain contact with members of the other group. The application of culture brought by the step-parent depends on how they practice the dimensions stated. Berry $(1990,2001)$ claims that people from different parts of the world face two major questions pertaining to their encounter with their new society: (a) whether to maintain their former cultural identity and (b) whether to develop closer relations with members of the host society and accept its values.

Step-children vary in their openness to developing bonds with step-parents and in their perceptions of step-parents' behaviors toward them (Ganong et al., 1999). Step-children who were school-aged and older when they met their step-parents expected the step-parents to initiate the first attempts to get to know them and to be nice to them (Ganong et al., 2011). When it comes to disciplining, several researchers have reported that step relationships are closer when step-parents take a supportive role with step-children and let biological parents do most of the disciplining (CrosbieBurnett\& Giles-Sims, 1994; Hetherington \&Clingempeel, 1992). Furthermore, authoritative step-parents - who favor high warmth and flexible control as a "parenting style" - have better relationships with step-children than authoritarian step-parents, who demonstrate low warmth and high control (Golish, 2003; Henry \& Lovelace, 1995) as step-children prefer open and flexible communication with step-parents (Baxter et al., 2004; Henry \& Lovelace, 1995). Speer and Trees (2007) found that step-children's interactions with a step-parent and the communicative strategies implemented to manage the step-parent's communicative ambiguity is associated with the step-child's perception of family relationship quality. The relationship between the step-child and the step-parent depends on how the step-parent plays his/her role in the family. As described by previous studies, the most common pattern of closeness between step-child and stepfather was feeling close to stepfather where $46 \%$ of the step-children reported, with $23 \%$ feeling not close, $15 \%$ being less close, and $16 \%$ having improving relationships (King \& Lindstrom, 2016). Whether stepfather-stepchild relationships remained close, remaining not to close, became close or less, two factors stood out in identifying between these four patterns of closeness from adolescence to young adulthood: the closeness of the relationship between the mother and the child and the quality of the relationship between the mother and the stepfather (King \& Lindstrom, 2016).

\section{ADAPTING STAGE}

Paul Schrodt (2016) has a study that examined the degree to which step-children's relational frames operate as explanatory mechanisms for the positive alliance between everyday talk and relational satisfaction in stepparent-stepchild relationships. Results indicated that step-children's everyday talk with their residential step-parent positively predicts their positive regard for the step-parent, the parental authority they grant the step-parent, and their affective certainty within the relationship. Visher, E. B., \&Visher, J. S. (2019) suggested that step-parents reveal and conceal from step-children out of the same motivations. Establishing good relationships, viewing step-children as own children, helping step-children with problems resulting from the divorce, and viewing step-children as "others" and indicates that step-parents experienced dialectical tensions between closedness and openness during the decision of revealing or concealing from step-children. Elsbeth Neil (2009) explained that adoptive parents involved in face-to-face contact arrangements were found to be more communicatively open than parents involved in letterbox contact. Children's emotional and behavioral development was not related to either the type of contact that they were having with their families at birth or the conversational openness of their step-parents. Yvette Solomon et al., (2002) elaborated that while both parents and their teenage children support to the idea of openness and honesty as the route to both intimacy and democracy, there are stains within the concept of openness because both parties have opposing goals in the trading of information. For parents, information gain means the retention of power and control, while for teenagers, withholding information from their parents ensures their privacy, power, and identity. Jeanne Segal, Ph.D., and Lawrence Robinson (2019) 
emphasized the way a blended family communicates. They believe that it says a lot about the level of trust between the members of the family. When communication is clear and distinct, there are more possibilities for connection and fewer opportunities for misunderstanding, whether it is between parent and child or step-parent and step-child.

Timberly L. Baker et al., (2016) explained that language might be a barrier not only in getting information out but also when families are present at the school for an event like family night. Gillian Coote Martin (2014) is convinced that cultural diversity in the office has grown as a trend over time with the increase of globalization. One effect is that employees belonging to different cultures usually have various ways of thinking and can thus analyze a matter from a variety of perspectives. Asking the employees that belong to the same culture to analyze the same matter, makes it difficult to achieve. Jeanne Segal, Ph.D., and Lawrence Robinson (2019) thought that most families have very contrasting ideas about how to spend annual events such as holidays, birthdays, and family vacations. Forcing kids might make them feel resentful about going along with someone else's routine. They suggested trying to find some common ground or create new traditions for a blended family. RusulAlrubail (2014) justified that it is essential to be mindful of the cultural differences in students' behavior. Being able to distinguish or recognize these cultural differences allows the instructor to form a safe environment for all students. It is important to understand these differences to be able to implement culturally responsive teaching and pedagogical practices to ensure the success of every student in the classroom.

Michaels (2006) believes that Children who felt respected by the step-parents tended to have more successful relationships. According to teens.webmd.com (2018), if you and your step-parent have similar personalities and interests, it may take less time to adjust. Nevertheless, relationships with step-parents can be complicated as they may be part-friend and part-parent. Getting used to the balance between the parent and the friend parts can take a while. Jeanne Segal, Ph.D. and Lawrence Robinson (2019) said that if children spend a long time in a one-parent family, or still nurture hopes of reconciling their parents, they may have difficulty accepting a new person. Celia NoreenaFalchi (2014) emphasized acceptance. She perceives acceptance as an essential mindset for stepfamilies (and perhaps even any other family type) for family members to be able to move on from issues of conflict and fairness, and towards forgiveness even if emotions take more time to adjust. Acceptance of the stepfamily situation was an important component when perceiving conflict situations as resolvable rather than as an inevitable and permanent consequence of being a stepfamily.

\section{CONCLUSION}

This qualitative study's purpose is to determine the common struggles of stepchildren as they live with their stepparents. The child-parent relationship has a significant influence on most aspects of the child's development. When optimal, parenting skills and behaviors have a positive impact on children's self-esteem, school achievement, cognitive development, and behavior. In addition to that, it aims to know how this sudden change affects the child's emotional, social, and cultural stability towards the situation. Moreover, when a stepfamily is formed, the members may have no shared histories, routines, and belief systems.

The findings suggest that the stepparents need to be introduced to the stepchildren slowly. The stepparents are introduced by their biological parents; as they become aware of the situation, most struggles to adapt. Although time varies from one stepchild to another, they are all capable of understanding the situation gradually. As soon as the stepchildren become knowledgeable, they commence the conversation and share values and culture with their stepparents.

Despite the many experiences the stepchildren face to overcome the struggles of forming a stepfamily that are featured in this study, there is still a possibility that some ideas are left unnoticed. Researchers may utilize this study as they identify additional prospects. A significant limitation of this study is mainly focused on the foreign stepfathers of Senior High School students. This study has shown that not all cases have a bad effect on children; there are still some cases wherein children do not experience any struggles in adjusting to the new phase of their life. These experiences depend on how and when they were introduced to their stepparents.

The researchers recommend this study to be further developed by future researchers by examining further, both theoretically and empirically. The researchers also suggest getting participants that have both genders as their stepparents and not only those who have stepfathers. The researchers also recommend to do deeper investigations and to lend more time towards this study as the researchers might miss some important factors that could help in strengthening this study.

\section{REFERENCES}

[1] A Stepchild's Sad Confession. (2013, March 22). Retrieved from https://www.huffpost.com/entry/nobody-asked-me-the-pligh_b_24428 $\underline{59}$

[2] Afifi, W. A., \&Burgoon, J. K. (1998). "We never talk about that": A comparison of cross-sex friendships and dating relationships on uncertainty and topic avoidance. Personal Relationships, 5(3), 255-272. Retrieved from https://search-proquest-com.eres.qnl.qa/docview/61592589?accountid $\equiv 49936$

[3] Alrubail, R. (2016, January 14). Being Mindful of Cultural Differences. $\quad$ Retrieved from https://www.edutopia.org/discussion/being-mindful-cultural-differenc $\underline{\text { es }}$

[4] Baker, T. L., Wise, J., Kelley, G., \&Skiba, R. J. (2016). Identifying Barriers: Creating Solutions to Improve Family Engagement. Retrieved from https://tinyurl.com/yx 5rq5ex

[5] Baxter, L. A., Braithwaite, D. O., Bryant, L., \& Wagner, A. (2004) Stepchildren's perceptions of the contradictions in communication with stepparents. Journal of Social and Personal Relationships, 21(4), 447-467. doi:http://dx.doi.org.eres.qnl.qa/10.1177/0265407504044841

[6] Berry, J. W. (1999). Intercultural relations in plural societies Canadian Psychology, 40(1), 12-21. Retrieved from https://search-proquest-com.eres.qnl.qa/docview/220814063?accounti $\underline{\mathrm{d}=49936}$ 
[7] Berry, J. W. (2001). A psychology of immigration. Journal of Social Issues, 57(3), 615-631. Retrieved from https://search-proquest-com.eres.qnl.qa/docview/38308130?accountid $=49936$

[8] [8] Ceballo, R., Lansford, J. E., Abbey, A., \& Stewart, A. J. (2004). Gaining a Child: Comparing the Experiences of Biological Parents, Adoptive Parents, and Stepparents. Family Relations, 53(1), 38-48. doi:10.1111/j.1741-3729.2004.00007.x

[9] Christopher, V. (1999, Jun 06). KNITTING TWO FAMILIES TOGETHER. Green Bay Press Gazette Retrieved from https://search-proquest-com.eres.qnl.qa/docview/892585096?accounti $\underline{\mathrm{d}=49936}$

[10] Claxton-Oldfield, S., Garber, T., \&Gillcrist, K. (2006). Young adults' perceptions of their relationships with their stepfathers and biological fathers. Journal of Divorce and Remarriage, 45(1-2), 51-61. doi:http://dx.doi.org.eres.qnl.qa/10.1300/J087v45n01 03

[11] Clingempeel, W. G., Brand, E., \&Ievoli, R. (1984). Stepparent-stepchild relationships in stepmother and stepfather families: A multimethod study. Family Relations, 33(3), 465-472. Retrieved from https://search-proquest-com.eres.qnl.qa/docview/61044345?accountid $\equiv 49936$

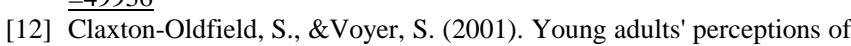
stepchildren. Journal of Divorce \& Remarriage, 35(1), 107. doi:http://dx.doi.org.eres.qnl.qa/10.1300/J087v35n01 06

[13] Coleman, M., Fine, M. A., Ganong, L. H.,Downs, K. J. M., \&Pauk, N. (2001). When you're not the Brady bunch: Identifying perceived conflicts and resolution strategies in stepfamilies. Personal Relationships,

$8(1)$ 55-73. https://doi.org/10.1111/j.1475-6811.2001.tb00028.x

[14] Creswell, J.W. (2013). Qualitative Inquiry \& Research Design: Choosing Among the Five Approaches.Thousand Oaks, CA: SAGE Publications, Inc. (pp. 77-83)

[15] Crosbie-Burnett, M., \& Giles-Sims, J. (1994). Adolescent adjustment and stepparenting styles. Family Relations, 43(4), 394. doi:http://dx.doi.org.eres.qnl.qa/10.2307/585370

[16] Cools, J. M. (2018, June 2). Being a Stepchild Really Sucks. Retrieved from

https://medium.com/@jmcools/being-a-stepchild-really-sucks-1c0d82 eff9ec.

[17] De Guzman, A. B., \& Tan, E. B. (2007). Educational Research Journal. Understanding the Essence of Scholarship From the Lived Experiences of a Select Group of Outstanding Filipino Researchers, 22(1), 53.

[18] DiVerniero, R. (2010). An intergroup perspective on stepchildren's communication with their nonresidential parent's family (Order No. 3398451). Available from ProQuest Central; ProQuest Dissertations \& Theses Global; Social Science Premium Collection. (250719303). Retrieved from https://search-proquest-com.eres.qnl.qa/docview/250719303?accounti $\underline{\mathrm{d}=49936}$

[19] Doyle, A. (2019). How Does a Semi-Structured Interview Work? [Web $\log$ post]. (2012, February 24). Retrieved from https://www.thebalancecareers.com/what-is-a-semi-structured-intervie $\underline{\mathrm{w}-2061632}$

[20] Falchi, C. N. (2014). Achieving positive stepfamily relationships : negotiating fairness, forgiveness, and acceptance : a thesis presented in partial fulfilment of the requirements for the degree of Doctor of Philosophy in Psychology at Massey University, Wellington, New Zealand. Retrieved from https://www.semanticscholar.org/paper/Achieving-positive-stepfamily -relationships-\%3A-and-\%3A-Falchi/763e12d92ea1683367e 9bfe5d72 Ofa80d0142728
[21] FRENIER, R. H. (1980). Structural Determinants Of Remarriage For Divorced And Widowed Persons (Order No. 8022022). Available from ProQuest Dissertations \& Theses Global. (303030805). Retrieved from https://search-proquest-com.eres.qnl.qa/docview/303030805?accounti $\mathrm{d}=49936$

[22] Ganong, L. H., Coleman, M., \& Jamison, T. (2011). Patterns of Stepchild-Stepparent Relationship Development. Journal of Marriage and Family, 73(2), 396-413. doi:10.1111/j.1741-3737.2010.00814.x

[23] García, F., \&Gracia, E. (2009). IS ALWAYS Golish, T. D. (1999). I'd rather not talk about it: Adolescents' and young adults' use of topic avoidance in stepfamilies (Order No. 9942123). Available from ProQuest Dissertations \& Theses Global. (304511983). Retrieved from https://search-proquest-com.eres.qnl.qa/docview/304511983?accounti $\mathrm{d}=49936$

[24] Golish, T. D. (2003). Stepfamily communication strengths: Understanding the ties that bind.Human Communication Research, 29(1), 41-80. Retrieved from https://search-proquest-com.eres.qnl.qa/docview/199380366?accounti $\underline{\mathrm{d}=49936}$

[25] Grace, E. (2017, July 30). Challenges of Being a Step Child. Retrieved from

http://www.beingastepparent.co.uk/challenges-being-step-child.html.

[26] Hetherington, E. \&Clingempeel, W. \& Anderson, Edward \& Deal, James \& Hagan, Margaret \&Hollier, E. \&Gunnoe, Marjorie \&MacCoby, Eleanor \& Brown, Jeanne \& O'Connor, Thomas \& Eisenberg, Marlene \& Rice, Alyson \&Bennion, L.. (1992). Coping with Marital Transitions: A Family Systems Perspective. Monographs of the Society for Research in Child Development. 57. i. 10.2307/1166050. Retrieved

from https://www.researchgate.net/publication/272594440 Coping with Marital_Transitions_A_Family_Systems_Perspective/citation/downlo $\underline{\mathrm{ad}}$

[27] Hetherington, E. M. (1992). Coping with marital transitions: A family systems perspective. Monographs of the Society for Research in Child Development, 57(2-3), 1-14. Retrieved from https://search-proquest-com.eres.qnl.qa/docview/62953126?accountid =49936

[28] Henry, C.S., Lovelace, S.G. (1995). Family Resources and Adolescent Family Life Satisfaction in Remarried Family Households.Retrieved from

https://journals.sagepub.com/doi/abs/10.1177/019251395016006005

[29] Kelly, M. T. (2013). Nobody Asked Me: The Plight Of The Reluctant Stepchild. $\quad$ Retrieved from https://www.huffpost.com/entry/nobody-asked-me-the-pligh_b_24428 $\underline{59}$

[30] King, V., \& Lindstrom, R. (2016). Continuity and Change in Stepfather-Stepchild Closeness Between Adolescence and Early Adulthood. Journal of Marriage and Family, 78(3), 730-743. doi:10.1111/jomf.12281

[31] Lou, W. E. (1998). Factors that contribute to satisfaction or dissatisfaction in stepfather-stepchild relationships. Perspectives in Psychiatric Care, 34(2), 25-35. Retrieved from https://search-proquest-com.eres.qnl.qa/docview/200703229?accounti $\underline{\mathrm{d}=49936}$

[32] Martin, G. C. (2014). The Effects Of Cultural Diversity In The Workplace. Journal of Diversity Management (JDM), 9(2), 89-92. doi:10.19030/jdm.v9i2.8974

[33] Mboniswa, Prince, U. S., \&Thwala, J. D. (2019, July 16). Experiences of growing up as a stepchild for young adults at university level: a qualitative approach. Retrieved from http://hdl.handle.net/10530/1754

[34] Michaels, M. L. (2006). Factors That Contribute to Stepfamily Success. Journal of Divorce \& Remarriage, 44(3-4), 53-66. doi:10.1300/j087v44n03 04

[35] Mills, D. M. (1984). A Model for stepfamily development. Family Relations, 33(3), 365-372). Retrieved from http://factsheets.okstate.edu/documents/t-2240-tips-for-successful-step families-help-im-a-stepparent/ 
[36] Neil, E. (2012). The Corresponding Experiences of Adoptive Parents and Birth Relatives in Open Adoptions. International Advances in Adoption Research for Practice, 269-293. doi:10.1002/9780470741276.ch12

[37] O'Kelly, L. (2005, Apr 24). Review: Meet the step-parents: The latest reality TV series has children picking a mate for their single parent. but how can new partners woo their lovers offspring? The Observer Retrieved from https://search-proquest-com.eres.qnl.qa/docview/250334542?accounti $\underline{\mathrm{d}=49936}$

[38] Olson, I. (2002, Apr 26). BABY STEPS EASE TRANSITION FOR STEPFAMILY IN NEW MARRIAGES. Wyoming Tribune Eagle Retrieved from https://search-proquest-com.eres.qnl.qa/docview/373682745?accounti $\underline{\mathrm{d}=49936}$

[39] Punch (2013). Journal of Economic Development, Environment and People, 7(01), 23-48.

[40] [40] Rainforth, P. (2018). Stepfamily expectations: Expected and actual communication between stepchildren and stepparents (Order No. 10814976). Available from ProQuest Dissertations \& Theses Global. (2070380842). Retrieved from https://search-proquest-com.eres.qnl.qa/docview/2070380842?account $\underline{\mathrm{id}=49936}$

[41] Roush, K. (2015). Relational dialectics in stepparent and stepchild relationships (Order No. 1587964). Available from ProQuest Dissertations \& Theses Global. (1681011422). Retrieved from https://search-proquest-com.eres.qnl.qa/docview/1681011422?account $\underline{\mathrm{id}=49936}$

[42] Segal, Ph.D., J., \& Robinson, L. (2019, November 15). Blended Family and Step-Parenting Tips. Retrieved from https://www.helpguide.org/articles/parenting-family/step-parenting-bl ended-families.htm

[43] Sheppard, P., Garcia, J. R., \& Sear, R. (2014). A not-so-grim tale: How childhood family structure influences reproductive and risk-taking outcomes in a historical U.S. population. PLoS One, 9(3) doi:http://dx.doi.org.eres.qnl.qa/10.1371/journal.pone.0089539

[44] Sherman, C. (Ed.). (2016, September). Living With Stepparents (for Kids) - Nemours KidsHealth. Retrieved from https://kidshealth.org/en/kids/blended.html..

[45] Shroff, A. (2018, April 23). Living With a Stepparent. Retrieved from https://teens.webmd.com/living-with-step-parent

[46] Social Science Research. (2012). Same-sex parenting and children's outcomes: A closer examination of the American psychological association's brief on lesbian and gay parenting, 41(4), 735-751.

[47] Schrodt, P. (2015). Relational frames as mediators of everyday talk and relational satisfaction in stepparent-stepchild relationships. Journal of Social and Personal Relationships, 33(2), 217-236. doi:10.1177/0265407514568751

[48] Solomon, Y., Warin, J., Lewis, C., \& Langford, W. (2002). Intimate Talk between Parents and their Teenage Children. Sociology, 36(4), 965-983. doi:10.1177/003803850203600409

[49] Visher, E. B., \&Visher, J. S. (2019). Working with Stepchildren. Stepfamilies, 181-206. doi:10.4324/9781315784236-11

[50] Wilchek-Aviad, Y., \&Timsit, A., M.A. (2018). Cultural adjustment strategy, level of identity consolidation and a sense of alienation among adults in the ethiopian community in israel. The Israel Journal of Psychiatry and Related Sciences, 55(3), 23-30,72. Retrieved from https://search-proquest-com.eres.qnl.qa/docview/2248967266 